\title{
A rare cutaneous tuberculosis form, erythema induratum of Bazin: 6 years' experience
}

\author{
Asude Kara Polat ${ }^{1 凶}$, Muge Gore Karaali ${ }^{1}$, Ayse Esra Koku Aksu ${ }^{1}$, Vefa Asli Turgut Erdemir ${ }^{2}$, Cem Leblebici ${ }^{3}$, Mehmet Salih \\ Gurel $^{2}$
}

${ }^{1}$ Department of Dermatology, University of Health Sciences, Istanbul Training and Research Hospital, Istanbul, Turkey. ${ }^{2}$ Department of Dermatology, Medeniyet University, Göztepe Training and Research Hospital, Istanbul, Turkey. ${ }^{3}$ Department of Pathology, University of Health Sciences, Istanbul Training and Research Hospital, Istanbul, Turkey.

\begin{abstract}
Introduction: Erythema induratum of Bazin (EIB) is a rare tuberculid form characterized by hypersensitivity to Mycobacterium tuberculosis antigens. There are a few case series related to EIB in the literature. We evaluated the demographic, clinical, treatment, and follow-up characteristics of patients diagnosed with EIB.

Methods: Demographic, clinical, histopathologic, and imaging findings as well as treatment and follow-up properties were evaluated in 22 patients retrospectively diagnosed with EIB between January 2013 and December 2018.

Results: Of the 22 patients, $90.9 \%$ were female and $9.1 \%$ were male. The mean age was $57.2 \pm 12.9$ years. Ten of the patients had a history of contact with tuberculosis, and one had a history of active pulmonary tuberculosis. The purified protein derivate (PPD) test average was $18.1 \mathrm{~mm}$. The lesions were located in the lower extremity in all patients and in the upper extremity in $31.8 \%$ of patients. Histopathologically, $22.7 \%$ had vasculitis, $27.3 \%$ were treated with four tuberculosis drugs, and $72.7 \%$ were followed without tuberculosis treatment. Treatment was continued for two patients, and $75.0 \%$ of the patients treated with a four-drug regimen recovered. Relapse was observed in one of the patients after 36 months. The recovery rate was found to be $87.5 \%$ in patients that did not receive tuberculosis treatment, and there were no relapses in the follow-up.

Conclusions: ElB's etiopathogenesis is unknown. In total, $75.0 \%$ of the patients receiving tuberculosis treatment and $87.5 \%$ of the patients without tuberculosis treatment recovered in our study. The role of tuberculous therapy in the management of ElB is controversial. The selection of appropriate treatment for EIB continues to be an area of debate, and further studies are needed.
\end{abstract}

Keywords: erythema induratum of Bazin, PPD, tuberculosis

Received: 11 April 2020 | Returned for modification: 5 July 2020 | Accepted: 4 August 2020

\section{Introduction}

Tuberculosis is an infectious granulomatous disease, often caused by Mycobacterium tuberculosis and characterized by pulmonary involvement. Among all forms of tuberculosis, the incidence of extrapulmonary tuberculosis has increased in recent years, and Sandgren et al. (1) reported an increase from $16.4 \%$ to $22.4 \%$. Out of all forms of tuberculosis, cutaneous tuberculosis comprises 1.0 to $1.5 \%(2)$.

In 1861, Bazin et al. described erythema induratum of Bazin (EIB) as chronic, recurrent, and subcutaneous violaceous and/ or erythematous painful nodules that may accompany ulcers in the posterior portion of the legs in obese middle-aged female patients. It is a rare tuberculid form characterized by hypersensitivity to Mycobacterium tuberculosis antigen (3-5). Although the disease is defined as nodular vasculitis, it is called EIB when a relation to tuberculosis is detected (6). Although the relationship of the disease to tuberculosis is suspicious, it is thought that the condition is related to tuberculosis antigens due to the detection of DNA in the microorganism with the polymerase chain reaction (PCR) in the tissue and the response of the disease to tuberculosis treatment $(5,7)$. Histopathologically, EIB is characterized by vasculitis accompanying lobular panniculitis. Giant cell-containing granuloma structures and neutrophil-dominant mixed inflammatory cell infiltration can also be seen (8). The diagnosis of EIB is based on the evidence of tuberculosis infection with a clinicopathological correlation (2).

There are no definitive guidelines that are proposed for the treatment of this disease. Treatment modalities including tuberculosis therapy, nonsteroidal anti-inflammatory drugs (NSAIDs), potassium iodine, dapsone, colchicine, antimalarial drugs, tetracycline, and systemic steroids may be preferred (5).

Upon evaluating the literature, one can find a few series of disease cases. Aside from a few large series related to EIB, the studies are often clinicopathologic, and there is limited information on the course of treatment for the disease $(9,10)$. This study evaluated the epidemiological, clinical, treatment, and follow-up characteristics of 22 patients with EIB.

\section{Material and methods}

This study retrospectively evaluated data on 22 patients clinically and histopathologically diagnosed with EIB between January 2013 and December 2018. The patients that could be reached by phone had their skin lesions re-evaluated at the outpatient clinic.

The patients' sociodemographic characteristics were evaluated, including age (years), sex, body mass index (BMI, $\mathrm{kg} / \mathrm{m}^{2}$ ), accompanying systemic and dermatological diseases, duration until diagnosis (months), total disease duration (months), clinical features including lesion localization, number of lesions, accom- 
panying symptoms, history of active tuberculosis, history of contact with a patient with Mycobacterium tuberculosis infection, history of tuberculosis treatment, and presence of a Bacillus Calmette-Guérin (BCG) vaccine. These characteristics also included laboratory properties, such as a purified protein derivate (PPD), T-SPOT-TB, chest X-ray, and thoracic computerized tomography. Histopathologic features were also included, such as lobular panniculitis, mixed panniculitis, presence of granuloma, type of cell infiltration, presence of vasculitis, positivity of Ehrlich-ZiehlNeelsen (EZN) staining for acid-fast bacilli, tissue PCR for Mycobacterium tuberculosis, skin culture for Mycobacterium tuberculosis infection, treatment properties, duration of follow-up, relapse, relapse after treatment, and relapse time.

\section{Statistical analysis}

In the descriptive statistics of the data, the mean, standard deviation, median lowest, highest, frequency, and ratio values were used. The distribution of the variables was measured by the Kolmogorov-Smirnov test, and the Mann-Whitney $U$ test was used for analysis of independent quantitative data. For the analysis of the independent qualitative data, the chi-square test was used, and Fischer's test was used when the chi-square test data were not provided. The program SPSS 22.0 was used in the analysis.

\section{Results}

\section{Sociodemographic properties}

Out of 22 patients, $20(90.9 \%)$ were female and two (9.1\%) were male, with a mean age of $57.2 \pm 12.9$ years. The mean BMI was $31.1 \mathrm{~kg} / \mathrm{m}^{2}$. Hypertension, hypothyroidism, and diabetes mellitus were the most common concomitant diseases. Seven patients (31.8\%) had hypertension, six $(27.3 \%)$ had hypothyroidism, and five $(22.7 \%)$ had diabetes mellitus. Only one $(4.5 \%)$ of the patients had a history of active pulmonary tuberculosis and tuberculosis lymphadenitis, and 10 patients (45.5\%) had a history of contact with a patient with a Mycobacterium tuberculosis infection. The characteristics of the study population are shown in Table 1.

\section{Clinical properties}

All the patients had lesions on their lower extremities, and these lesions were frequently localized on the anterior portion of the legs. In order of frequency, nine patients (40.9\%) had lesions on their anterior and posterior legs, $40.9 \%$ had lesions on the anterior legs only, and $18.2 \%$ had lesions on the posterior legs. Clinical photographs of patients with EIB in various locations are shown in Figure 1.

Three patients (13.6\%) had one isolated lesion, nine patients ( $40.9 \%$ ) had two to five lesions, and 10 patients (45.5\%) had more than five lesions. Seventeen (77.3\%) patients were symptomatic, and the most common symptom was pain, with $88.0 \%$ experiencing it. All the patients had nodular lesions, and four patients (18.2\%) had ulcers.

\section{Laboratory and histopathologic properties}

Sixteen patients' $(72.7 \%)$ computerized tomography of the thorax revealed tuberculosis findings (apical sequelae). Among these, three patients (13.6\%) had already shown abnormalities in their chest X-rays. Latent tuberculosis infection was confirmed by a PPD test or by T-SPOT-TB positivity in all patients except for one, for whom some medical records were not available. The mean PPD levels of the patients were $18.1 \mathrm{~mm}$ ( $\mathrm{min}$. o mm, max. $32 \mathrm{~mm}$ ), and the PPD test was anergic in one patient (4.5\%), but the T-SPOT-TB test was positive for this patient.

EZN staining was performed in 18 patients (81.8\%), and all

Table 1 | Sociodemographic properties, comorbidities, and histories of the study population $(n=22)$.

\begin{tabular}{|c|c|}
\hline Variable & $n(\%)$ or mean \pm SD \\
\hline \multicolumn{2}{|l|}{ Sex } \\
\hline Female & $20(90.9)$ \\
\hline Male & $2(9.1)$ \\
\hline Age (years) & $57.2 \pm 12.9$ \\
\hline BMI $\left(\mathrm{kg} / \mathrm{m}^{2}\right)$ & $31.1 \pm 7.8$ \\
\hline Duration until diagnosis (months) & $8.8 \pm 10.1$ \\
\hline PPD (mm) & $18.1 \pm 7.1$ \\
\hline Follow-up (months) & $26.5 \pm 16.4$ \\
\hline Duration of disease (months) & 16.0 \\
\hline \multicolumn{2}{|l|}{ Comorbidities } \\
\hline Hypertension & $7(31.8)$ \\
\hline Hypothyroidism & $6(27.3)$ \\
\hline Diabetes mellitus & $5(22.7)$ \\
\hline Chronic HCV infection & $1(4.5)$ \\
\hline Chronic HCV + HBV infection & $1(4.5)$ \\
\hline \multicolumn{2}{|l|}{ BCG vaccine } \\
\hline Present & $20(90.9)$ \\
\hline Absent & $2(9.1)$ \\
\hline \multicolumn{2}{|l|}{ History of active tuberculosis } \\
\hline Present & $1(4.5)$ \\
\hline Absent & $20(90.9)$ \\
\hline Unknown & $1(4.5)$ \\
\hline \multicolumn{2}{|l|}{ History of contact with tuberculosis } \\
\hline Present & $10(45.5)$ \\
\hline Absent & $10(45.5)$ \\
\hline Unknown & $2(9.1)$ \\
\hline \multicolumn{2}{|l|}{ History of tuberculosis treatment } \\
\hline Present & $1(4.5)$ \\
\hline Absent & $20(90.9)$ \\
\hline Unknown & $1(4.5)$ \\
\hline
\end{tabular}

$\mathrm{BMI}=$ body mass index; $\mathrm{PPD}=$ purified protein derivate; $\mathrm{HCV}=$ hepatitis $\mathrm{C}$ virus; $\mathrm{HBV}=$ hepatitis $\mathrm{B}$ virus; $\mathrm{BCG}=$ Bacillus Calmette-Guérin; $\mathrm{SD}=$ standard deviation.

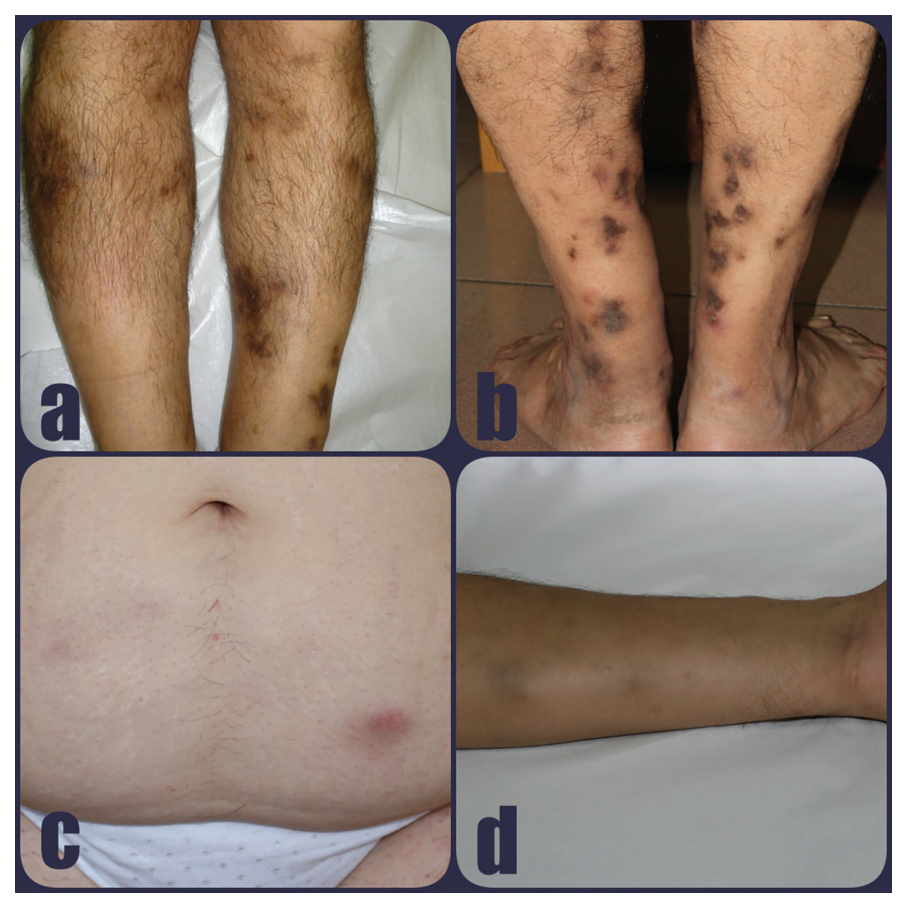

Figure 1 | Clinical photographs of patients with erythema induratum of Bazin (EIB) in various locations. 
were negative. In six (27.3\%) patients, tissue culture and PCR were performed, and all were negative.

All biopsy specimens were lobular, 12 (54.5\%) showed mixedtype panniculitis, and $10(45.5 \%)$ had isolated lobular panniculitis. In addition, all histopathologic specimens showed tuberculoid granuloma formation. In five $(22.7 \%)$ biopsy specimens, vasculitis was observed. The histopathologic features of patients with EIB are shown in Figure 2, and the clinical and histopathologic properties of the study population are shown in Table 2.

\section{Treatment and follow-up properties}

Six patients $(27.3 \%)$ were treated with antituberculosis agents, and $16(72.7 \%)$ were followed without antituberculosis agents. The tuberculosis treatment of two patients is continuing, and $75.0 \%(3 / 4)$ of the patients that were treated with tuberculosis

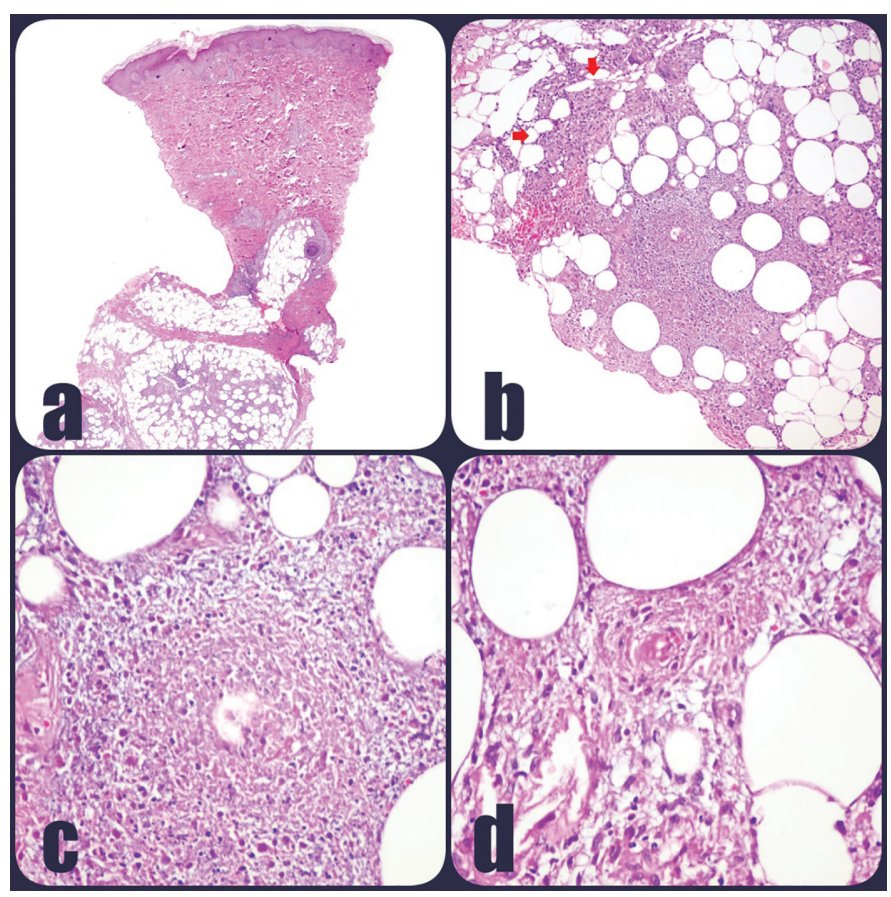

Figure 2 | a) Intensive inflammatory cell infiltration involving the middle lobule in the subcutaneous adipose tissue (HE $\times 40)$. b) Granuloma-forming histiocytes surrounding a large area of necrosis (red arrow; HE $\times 2,000$ ). c) Eosinophilic necrotic debris (HE $\times 400)$. d) Fibrinoid necrosis of the small-diameter vessel wall $(\mathrm{HE} \times 400)$. drugs recovered. Relapse was observed in one of the recovered patients after 36 months, without treatment. In total, $87.5 \%$ of the patients $(14 / 16)$ that were followed up without tuberculosis drugs were cured and did not show any signs of relapse. The flow diagram of the patients is shown in Figure 3.

In 11 patients (50.0\%), the disease regressed with only hyperpigmentation, in six (27.2\%) with hyperpigmentation and scarring, and in three (13.6\%) without hyperpigmentation or scarring. In two patients $(12.5 \%)$ the scarring could not be evaluated because the patients were lost due to non-EIB-related reasons (hepatocellular carcinoma and myocardial infarction).

When the treatment groups with and without tuberculosis therapy were compared, the presence of lesions in different regions of Table 2 | Clinical and histopathologic properties of the study population.

\begin{tabular}{|c|c|}
\hline Variable & $n(\%)$ \\
\hline \multicolumn{2}{|l|}{ Number of lesions } \\
\hline 1 & $3(13.6)$ \\
\hline $2-5$ & $9(40.9)$ \\
\hline$>5$ & $10(45.5)$ \\
\hline \multicolumn{2}{|l|}{ Localization } \\
\hline Legs, anterior & $9(40.9)$ \\
\hline Legs, posterior & $4(18.2)$ \\
\hline Legs, anterior + posterior & $9(40.9)$ \\
\hline Thigh & $8(36.4)$ \\
\hline Upper extremity & $7(31.8)$ \\
\hline Trunk & $3(13.6)$ \\
\hline \multicolumn{2}{|l|}{ Lesion in different localizations } \\
\hline Present & $10(45.5)$ \\
\hline Absent & $12(54.5)$ \\
\hline \multicolumn{2}{|l|}{ Symptoms } \\
\hline Present & $17(77.3)$ \\
\hline Absent & $5(22.7)$ \\
\hline \multicolumn{2}{|l|}{ Panniculitis type } \\
\hline Mixed & $12(54.5)$ \\
\hline Lobular & $10(45.5)$ \\
\hline \multicolumn{2}{|l|}{ Granuloma } \\
\hline Present & $22(100.0)$ \\
\hline Absent & $0(0.0)$ \\
\hline \multicolumn{2}{|l|}{ Infiltration } \\
\hline Lymphocytic & $17(77.3)$ \\
\hline Lymphocytic + neutrophilic & $5(22.7)$ \\
\hline \multicolumn{2}{|l|}{ Fat necrosis } \\
\hline Present & $21(95.5)$ \\
\hline Absent & $1(4.5)$ \\
\hline \multicolumn{2}{|l|}{ Vasculitis } \\
\hline Present & $5(22.7)$ \\
\hline Absent & $17(77.3)$ \\
\hline
\end{tabular}

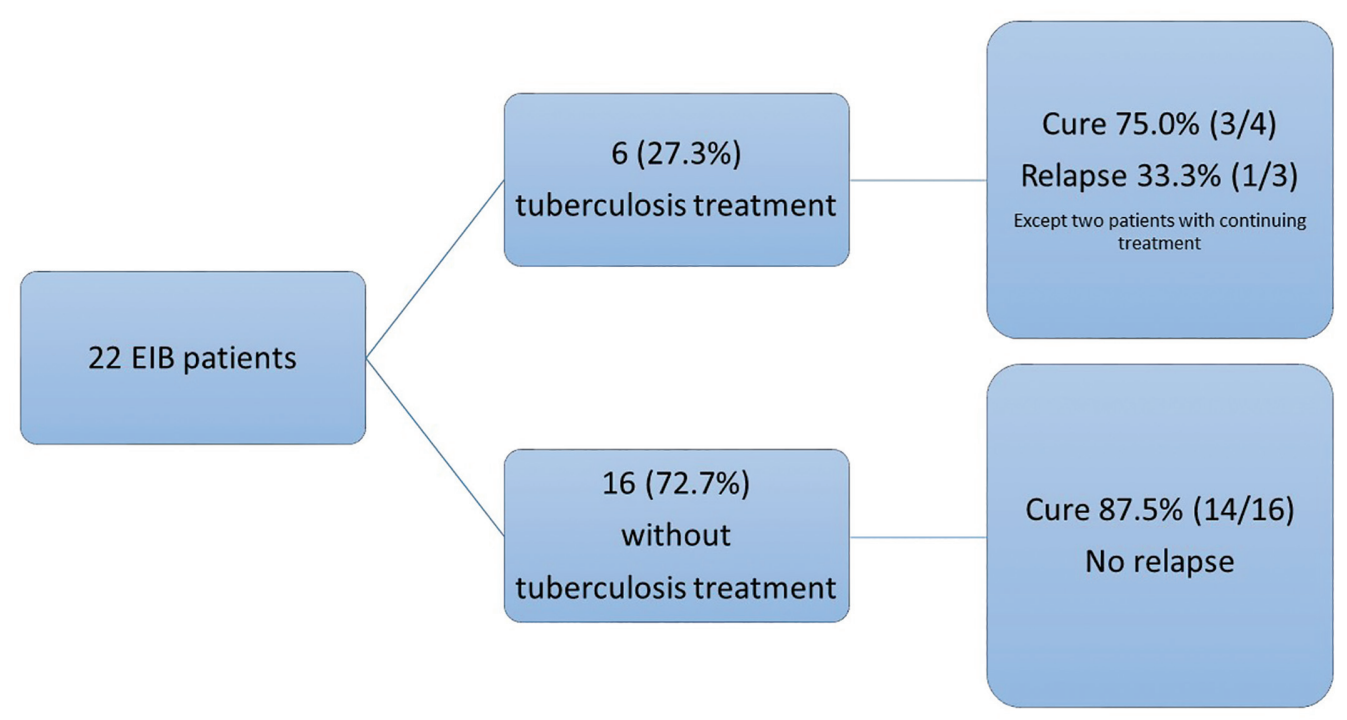

Figure 3 | Flow diagram of patients with erythema induratum of Bazin (EIB). 
the body was significantly higher $(p<0.05)$. At the same time, the other parameters were not statistically significant, and the treatment response and the relapse rate did not differ significantly ( $p>$ o.05). The properties of both groups are shown in Table 3.

The mean disease duration was 16 months, and the mean follow-up period was $26.5 \pm 16.4$ months (min. 2 months, max. 58 months).

\section{Discussion}

Cutaneous tuberculosis can appear as primary cutaneous tuberculosis by direct inoculation, scrophuloderma, periorificial tuberculosis, tuberculosis verrucosa cutis, lupus vulgaris, and tuberculids. Tuberculids can appear as papulonecrotic tuberculids, lichen scrofulosorum, and EIB (2). EIB is a disease characterized by subcutaneous asymptomatic or painful nodules on the posterior part of the legs, in which the isolated lesions can recede and new lesions can be seen, which can last for years in middle-aged women (10).

The relationship between EIB and tuberculosis is controversial. It has also been reported that there may be a reactive situation due to high BMI, cold climate, chronic venous insufficiency, or previous deep venous thrombosis in the regions where the incidence of tuberculosis is low (10). Mycobacterium tuberculosis cannot always be cultured in the biopsies, and Mycobacterium tuberculosis DNA cannot always be detected by tissue PCR $(5,7)$. Baselga et al. (7) reported 77.0\% PCR positivity, whereas Schneider et al. (11) reported a rate of $25.0 \%$. Connors et al. (12) and Mann et al. (13) reported that all tissue biopsies in their series were negative for cultures and mycobacterial stainings.

The absence of Mycobacterium tuberculosis bacilli in tuberculid skin lesions may be explained by the fact that the bacterium may be destroyed by the immunological mechanism, and the skin lesions may exist because of a systemic reaction to Mycobacterium tuberculosis fragments in the serum (14). A PPD test or a positive interferon-gamma release assay (IGRA) test in patients with EIB can support the association of the disease with Mycobacterium tuberculosis $(5,14)$. Posada Garcia et al. (15) reported EIB at the injection site of the PPD test, and this condition was also confirmed histopathologically. This case supports the association of $\mathrm{Myco}$ bacterium tuberculosis with the disease.

In individuals with BCG vaccinations in Turkey, the PPD is considered positive if it is above $15 \mathrm{~mm}$ as well as in cases without BCG vaccination over $10 \mathrm{~mm}$ (16). Erdemir et al. (17) assessed 62 patients with a painful subcutaneous nodule and found EIB in six patients. All of the patients reported that the PPDs were over 22

Table 3 | Comparison of properties of groups with and without tuberculosis treatment.

\begin{tabular}{|c|c|c|c|}
\hline Variable & $\begin{array}{l}\text {-Treatment, } n=16 \\
n(\%) \text { or mean } \pm \text { SD }\end{array}$ & $\begin{array}{l}+ \text { Treatment, } n=6 \\
n(\%) \text { or mean } \pm \text { SD }\end{array}$ & $p$ \\
\hline Age & $59.7 \pm 11.8$ & $50.7 \pm 14.4$ & $0.130^{\mathrm{m}}$ \\
\hline \multicolumn{4}{|l|}{ Sex } \\
\hline Female & $14(87.5)$ & $6(100.0)$ & $1.000^{x^{2}}$ \\
\hline Male & $2(12.5)$ & $0(0.0)$ & \\
\hline $\mathrm{BMI}\left(\mathrm{kg} / \mathrm{m}^{2}\right)$ & $31.3 \pm 7.3$ & $30.8 \pm 9.3$ & $0.637^{m}$ \\
\hline Duration until diagnosis (months) & $7.2 \pm 8.3$ & $13.0 \pm 13.9$ & $0.204^{\mathrm{m}}$ \\
\hline $\mathrm{PPD}(\mathrm{mm})$ & $17.3 \pm 8.4$ & $19.7 \pm 3.2$ & $0.311^{\mathrm{m}}$ \\
\hline Follow-up (months) & $25.3 \pm 17.1$ & $29.5 \pm 15.7$ & $0.712^{m}$ \\
\hline Duration of treatment (months) & & $7.5 \pm 1.7$ & - \\
\hline \multicolumn{4}{|l|}{ BCG vaccine } \\
\hline Present & $14(87.5)$ & $6(100.0)$ & $1.000^{x^{2}}$ \\
\hline Absent & $2(12.5)$ & $0(0.0)$ & \\
\hline \multicolumn{4}{|l|}{ History of active tuberculosis* } \\
\hline Present & $0(0.0)$ & $1(16.7)$ & $0.286^{x^{2}}$ \\
\hline Absent & $15(100.0)$ & $5(83.3)$ & \\
\hline \multicolumn{4}{|l|}{ History of contact with tuberculosis* } \\
\hline Present & $8(57.1)$ & $2(33.3)$ & $0.329^{x^{2}}$ \\
\hline Absent & $6(42.9)$ & $4(66.7)$ & \\
\hline \multicolumn{4}{|l|}{ History of tuberculosis treatment* } \\
\hline Present & $0(0.0)$ & $1(16.7)$ & $0.286^{x^{2}}$ \\
\hline Absent & $15(100.0)$ & $5(83.3)$ & \\
\hline \multicolumn{4}{|l|}{ Number of lesions } \\
\hline $1-5$ & 11 & 1 & $0.088^{x^{2}}$ \\
\hline$>5$ & 5 & 5 & \\
\hline \multicolumn{4}{|l|}{ Lesion in different localizations } \\
\hline Present & 4 & 6 & $0.002^{x^{2}}$ \\
\hline Absent & 12 & 0 & \\
\hline \multicolumn{4}{|l|}{ Symptoms (pain, ulcer, etc.) } \\
\hline Present & 12 & 5 & $1.000^{x^{2}}$ \\
\hline Absent & 4 & 1 & \\
\hline Tuberculosis findings in imaging & & & \\
\hline Present & $\begin{array}{c}11 \\
5\end{array}$ & 5 & $0.634^{x^{2}}$ \\
\hline Absent & 3 & 1 & \\
\hline \multicolumn{4}{|l|}{ Treatment response* } \\
\hline Present & 14 & 6 & $1.000^{x^{2}}$ \\
\hline Absent & 0 & 0 & \\
\hline \multicolumn{4}{|l|}{ Relapsing* } \\
\hline Present & 0 & 1 & $0.273^{x^{2}}$ \\
\hline Absent & 16 & 5 & \\
\hline
\end{tabular}

$\mathrm{BMI}=$ body mass index; $\mathrm{PPD}=$ purified protein derivate; $\mathrm{BCG}=$ Bacillus Calmette-Guérin; $\mathrm{SD}=$ standard deviation .

${ }^{\mathrm{m} M a n n-W h i t n e y} U$ test, ${ }^{x^{2}}$ chi-square test (Fischer's test), * statistics based on available patient data. 
$\mathrm{mm}$. As a result, the researchers suggested a more detailed evaluation for tuberculosis in patients with panniculitis and with PPD over $20 \mathrm{~mm}$. The mean PPD value in our study was $18.1 \mathrm{~mm}$. In one of the patients, the PPD was found to be anergic, and the TBSPOT test was positive in confirming latent tuberculosis infection. This patient had a chronic hepatitis $\mathrm{C}$ (HCV) infection and had not received any treatment.

EIB lesions are typically localized on the posterior of the legs $(3,9,10)$. In our study, unlike in the literature, the lesions were often localized on the anterior of the legs. Obesity has been defined as a risk factor for EIB (10), and in our study the disease was correlated with high BMI levels. In our patients, the diseases that may accompany EIB frequently included hypertension (31.8\%), hypothyroidism (27.3\%), and diabetes mellitus (22.7\%). In a study evaluating 86 patients with EIB, Seguro et al. (10) reported that the disease could be accompanied by superficial thrombophlebitis, rheumatoid arthritis, Crohn's disease, chronic lymphocytic leukemia, hypothyroidism, hepatitis B (HBV) infection, and HCV infection. In our study, one patient had a chronic HCV infection, and one patient had a HBV and HCV infection.

EIB is a granulomatous disease characterized by lobular panniculitis accompanied by vasculitis with possible necrosis (10). Although lobular panniculitis was seen in all the patients in our study, the mixed type was most commonly observed. EIB is also referred to as nodular vasculitis. The etiology of nodular vasculitis is considered to involve a hypersensitivity reaction due to chronic inflammatory diseases such as sarcoidosis and chronic HCV infection. Evidence of the association with tuberculosis is essential for the characterization of the disease as $\operatorname{EIB}(6,10)$. Vasculitis was detected in $55.6 \%$ of 54 biopsies in one study and $90.1 \%$ of 101 biopsies in another. They emphasized that the presence of vasculitis was not an absolute criterion in the diagnosis of $\operatorname{EIB}(9,10)$. Our study found vasculitis in $22.7 \%$ of the patients, and it was lower than reported in the literature. This rate may relate to the lack of evaluation for the pathology preparations in the serial sections.

There is no definitive guide for the management of EIB; however, classical cutaneous tuberculosis treatment is frequently applied (12, 18). Potassium iodide, systemic steroid, dapsone, colchicine, thalidomide, NSAID, methotrexate, and azathioprine can also be used (5). In their study evaluating 54 patients with EIB, Magalhães et al. (9) found that $90.8 \%$ of the patients responded to tuberculosis treatment; however, $53.7 \%$ of the patients experienced a relapse, which was more frequent in older patients. Tu- berculosis therapy is often administered with a four-drug regimen for 2 months, followed by a two-drug regimen for 6 to 9 months. A three- or four-drug regimen for 9 months is also recommended (5, 9). Connors et al. reported in their series that all 21 patients with EIB were treated with tuberculosis therapy with a mean duration of 6 months, and $80.0 \%$ of the patients resolved or improved their clinical signs. However, $14.0 \%$ of the patients experienced a severe adverse drug reaction, including hepatotoxicity, rash, gastrointestinal intolerance, and severe fatigue (12). In a series of 75 cases with cutaneous tuberculosis, $50 \%$ of the EIB patients experienced recurrence, and all these patients were treated with antituberculosis agents (13). In contrast to the literature, in our study, only $27.3 \%$ of the patients received tuberculosis treatment, and the majority $(72.7 \%)$ of the patients were followed up without treatment. The patients were treated with a four-drug regimen for 2 months, followed by a two-drug regimen for 6 months or 9 months. Half of the patients were treated for 6 months, and the other half were treated for 9 months with tuberculosis therapy, with four drugs for 2 months followed by two drugs. The treatment was successful in $75.0 \%$ of patients, and there was a histopathologically proven relapse in one patient at the 36 th month that regressed without treatment and received 6 months of tuberculous treatment. This finding was different from the literature. Among the patients followed up without antituberculosis agents, $87.5 \%$ also recovered, and there was no relapse in the follow-up period.

When the treatment groups with and without tuberculosis therapy were compared, the treatment response and the relapse rate did not differ significantly ( $p>0.05)$. This suggests that EIB is a hypersensitivity disease, regardless of the etiology, and that Mycobacterium tuberculosis needs to be reconsidered as the most important factor in the pathogenesis of the disease. The selection of appropriate treatments for EIB also continues to be an area of debate.

\section{Conclusions}

The etiopathogenesis of EIB is unclear. In our study, $75.0 \%$ of the patients receiving tuberculosis treatment and $87.5 \%$ of the patients without tuberculosis treatment recovered. The role and importance of tuberculosis treatment in the management of the disease and Mycobacterium tuberculosis in the pathogenesis of the disease are controversial. There is a need for additional studies, including comprehensive and larger series involving patients with EIB.

\section{References}

1. Sandgren A, Hollo V, van der Werf MJ. Extrapulmonary tuberculosis in the European Union and European Economic Area, 2002 to 2011. Euro Surveill. 2013;18: 20431.

2. Bravo FG, Gotuzzo E. Cutaneous tuberculosis. Clin Dermatol. 2007;25:173-80.

3. Bazin E. Extrait des Leçons théoriques et cliniques sur le scrofule. 2nd ed. Paris: Delhaye; 1861.

4. Van Zyl L, du Plessis J, Viljoen J. Cutaneous tuberculosis overview and current treatment regimens. Tuberculosis (Edinb). 2015;95:629-38.

5. Mascaro JM, Baselga E. Erythema induratum of Bazin. Dermatol Clin. 2008;26: 439-45.

6. Vera-Kellet C, Peters L, Elwood K, Dutz JP. Usefulness of interferon-g release assays in the diagnosis of erythema induratum. Arch Dermatol. 2011;147:949-52.

7. Baselga E, Margall N, Barnadas MA, Coll P, de Moragas JM. Detection of Mycobacterium tuberculosis DNA in lobular granulomatous panniculitis (erythema induratum-nodular vasculitis). Arch Dermatol. 1997;133:457-62.

8. Cho KH, Lee DY, Kim CW. Erythema induratum of Bazin. Int J Dermatol. 1996;35: 802-8.

9. Magalhães TS, Dammert VG, Samorano LP, Litvoc MN, Nico MMS. Erythema induratum of Bazin: epidemiological, clinical and laboratorial profile of $54 \mathrm{pa}$ tients. J Dermatol. 2018;45:628-9.

10. Segura S, Pujol RM, Trindade F, Requena L. Vasculitis in erythema induratum of Bazin: a histopathologic study of 101 biopsy specimens from 86 patients. J Am Acad Dermatol. 2008;59:839-51.

11. Schneider JW, Geiger DH, Rossouw DJ, Jordaan HF, Victor T, van Helden PD. Mycobacterium tuberculosis DNA in erythema induratum of Bazin. Lancet. 1993;342: 747-8.

12. Connors WJ, Fisher DA, Kunimoto DY, Jarand JM. Program-wide review and follow-up of erythema induratum of Bazin and tuberculosis-associated ocular inflammation management in a TB low-incidence setting: need for improved treatment candidate selection, therapy standardization, and care collaboration. BMC Infect Dis. 2019;19:97. 
13. Mann D, Sant'Anna FM, Schmaltz CAS, Rolla V, Freitas DFS, Lyra MR, et al. Cutaneous tuberculosis in Rio de Janeiro, Brazil: description of a series of 75 cases. Int J Dermatol. 2019;58:1451-9.

14. Lighter J, Tse DB, Li Y, Borkowsky W. Erythema induratum of Bazin in a child: evidence for a cell-mediated hyper-response to Mycobacterium tuberculosis. Pediatr Infect Dis J. 2009;28:326-8.

15. Posada Garcia C, Pena A, Anibarro L, Pardavila RM, De La Torre C, GonzálezFernández A. Erythema induratum of Bazin induced by tuberculin skin test. Int J Dermatol. 2015;54:1297-9.
16. Özkara Ş, Aktaş Z, Özkan S, Ecevit H. Türkiye'de tüberkülozun kontrolü için başvuru kitabı. Ankara: TC Sağlık Bakanlığı Verem Savaş Daire Başkanlığı; 2003.

17. Erdemir AV, Bağcı IS, Yamen Erdil D, Turan E. Retrospective evaluation of subcutaneous painful nodules. Istanbul Med J. 2013;14:80-2.

18. Nahid P, Dorman SE, Alipanah N, Barry PM, Brozek JL, Cattamanchi A, et al. Official American Thoracic Society / Centers for Disease Control and Prevention / Infectious Diseases Society of America clinical practice guidelines: treatment of drug-susceptible tuberculosis. Clin Infect Dis. 2016;63:e147-95. 